\title{
Methods for detection of Helicobacter pylori from stool sample: current options and developments
}

\author{
Enming Qiu ${ }^{1}$ (D) Zhou Li $^{1}$ (D) Shuai $\operatorname{Han}^{1}$ (i)
}

Received: 25 April 2021 / Accepted: 3 August 2021 / Published online: 15 August 2021

(c) The Author(s) 2021

\begin{abstract}
Accurate detection of Helicobacter pylori infection and determination of antibiotics have significant meaning in clinical practice. The detection methods can be categorized into two types, invasive and non-invasive, but nowadays we use the urease breath test most frequently which is non-invasive. However, many developing countries cannot meet the requirements for having specialized equipment and they lack trained personnel. Also, for the children, it is difficult to make them cooperate for the test. Methods that detect Helicobacter pylori from stool sample can be a promising alternative for detection used in children and mass screening. Stool antigen tests have several advantages such as rapidity, simplicity, and cheapness, though their results may be influenced by the heterogenicity of antigens, the nature of biochemical techniques, and the amount of antigen presented in the stool. PCR-based methods can specifically detect Helicobacter pylori infection and antibiotic resistance by targeting specific gene sequence, but they also are limited by the requirements of facilities and experts, the existence of inhibitory substance, and interference from the dead bacteria. Some novel methods also deserve our attention. Here we summarized the results of researches about methods using stool sample and we hope our work can help clinicians choose the appropriate test in clinical practice.
\end{abstract}

Keywords Helicobacter pylori $\cdot$ Stool sample $\cdot$ Stool antigen test $\cdot$ Polymerase chain reaction $\cdot$ Diagnostic method

\section{Introduction}

Helicobacter pylori (H. pylori) is a gram-negative pathogenic bacterium that was defined by Marshall and Warren [1], and this bacterium is responsible for several diseases, such as chronic gastritis, peptic ulcer, and gastric cancer [2]. Although most of $H$. pylori-infected patients are asymptomatic and only a small proportion of these patients will progress to peptic ulcer and gastric cancer after long-term

Responsible Editor: Jorge Luiz Mello Sampaio

Zhou Li

gzlizhou@smu.edu.cn

Shuai Han

gzhanbo0624@smu.edu.cn

Enming Qiu

13538118693@163.com

1 General Surgery Center, Department of Gastrointestinal Surgery, Zhujiang Hospital, Southern Medical University, Haizhu District, No.253. Gongye Middle Avenue, Guangzhou, Guangdong 510280, China infection [3], it still became one of the main causes of high mortality and morbidity worldwide. It is estimated that $50 \%$ of global population was infected by $H$. pylori $[4,5]$ which may lead to the increase of gastric cancer patients. Therefore, we need rapid, accurate, and convenient diagnostic methods to detect the $H$. pylori infection for the primary prevention of gastric cancer.

For decades, we have already developed several tools for detection of $H$. pylori and we can simply classify them as invasive methods and non-invasive methods [6]. Invasive methods include histology, culture, and rapid urease test whereas non-invasive methods include urea breath test, stool antigen test, serological test, and polymerase chain reaction (PCR). Because invasive methods cause discomfort for the patients, non-invasive methods are more commonly used in clinical practice. Detection of $H$. pylori from stool sample is non-invasive and easy to perform in epidemiological studies and diagnosis of infection in children. However, few review articles focus on these methods. Here we review the research about methods for detection of $H$. pylori from stool sample and the current progress (Table 1). 
Table 1 Brief description for advantages and disadvantages of both methods

\begin{tabular}{llll}
\hline Stool antigen test & Polymerase chain reaction & & \\
\cline { 2 - 4 } Advantages & Disadvantages & Advantages & Disadvantages \\
\hline Easy to sampling & Difference among antigens & Detection of virulence factor & $\begin{array}{c}\text { Requirements of specialized equipment and } \\
\text { trainees }\end{array}$ \\
Easy to transport & Low concentration of antigen in stool & Detection of antimicrobial resistance & $\begin{array}{c}\text { False positive results caused by DNA from } \\
\text { dead bacteria }\end{array}$ \\
Inexpensive & Subjective interpretation & Rapid testing of large samples & $\begin{array}{c}\text { False negative results caused by DNA } \\
\text { mutations }\end{array}$ \\
\hline
\end{tabular}

\section{Stool antigen test}

Stool antigen test (SAT) is a method used for direct detection of $H$. pylori antigen which exists in the feces. The diagnostic performances of different SATs are heterogeneous, and this may relate to the designs of the test like enzyme immunoassay (EIA) and immunochromatographic assay (ICA) and for the selection of antibody, such as monoclonal antibody and polyclonal antibody. Researchers have studied a lot to find out which test has the better diagnostic performance.

Some researchers assessed few of the commercial kits available recently. Halland et al. [7] assessed the performance of two novel enzyme immunoassays, the $\mathrm{H}$. PYLORI QUIK CHEK ${ }^{\mathrm{TM}}$ and the H. PYLORI CHEK ${ }^{\mathrm{TM}}$ assays. They demonstrated that the sensitivities of these two detection kits were $92 \%$ and $91 \%$, respectively; the specificity of these assays was $91 \%$ and $100 \%$, respectively. Furthermore, they did not observe any cross-reactivity against other gut pathogen. Fang et al. [8] enrolled 347 adult subjects including 152 volunteers and 195 symptomatic patients, and they reported that the sensitivity, specificity, and accuracy of the Vstrip HpSA were 91\%, 97\%, and $95.7 \%$ respectively, which makes it a potential method for mass screening of $H$. pylori infection. Opekun et al. [9] evaluated the automated LIAISON® Meridian $H$. pylori SA assay, a chemiluminescent immunoassay. They combine different methods including histology, culture, and rapid urease detection test and took that as standard, and finally they compare these results with automated LIAISON® Meridian $H$. pylori SA assay results; among these two the latter indicated a great sensitivity and specificity $(95.5 \%, 97.6 \%$, respectively) which ultimately showed good agreement with the standards.

Several researches have demonstrated that stool antigen test could give more information to clinician and they can extend its application. Kakiuchi et al. [10] evaluated $H$. pylori antigen detection kit named Quick Chaser $H$. pylori (QCP) which targeted the flagellar protein of $H$. pylori, while other commercial kits usually targeted the catalase of H. pylori. They compared QCP with another stool antigen detection kit such as Testmate rapid pylori antigen (TRP) while using the rapid urease test and culture as standard. They found that the QCP had great sensitivity and specificity for detection of $H$. pylori infection and it was also sensitive to clarithromycin (CAM)-resistant isolates and CAM-susceptible isolates.

Moon et al. [11] showed that $H$. pylori antigen presented in stool was independently associated with a higher serum pepsinogen (PG) I level and a lower serum PG I/II ratio, which indicate that the patient has an active current $H$. pylori infection with increased gastric secreting ability. Yan et al. [12] showed that the SAT has the same diagnostic value in patients with distal gastrectomy as in patients without surgery.

The comparison of diagnostic performance among different stool antigen tests attracted many researchers' interests. Zhou et al. [13] conducted a meta-analysis including 45 studies, and they concluded that SAT using ELISA monoclonal antibodies is an efficient test for the diagnosis of infection in children, yet the available polyclonal SAT tests may still be unreliable. Korkmaz et al. [14] compared the performance of $5 \mathrm{HpSA}$ assay for diagnosing $H$. pylori infection in symptomatic adult patients before they accepted eradication therapy and found that Premier Platinum HpSA Plus test was the most accurate testing for the diagnosis of H. pylori infection, with $92.2 \%$ for sensitivity and $94.4 \%$ for specificity.

The guidelines for the management of Helicobacter pylori infection in Japan suggested that the SAT has great diagnostic performance, with sensitivity of $96-100 \%$ and specificity of $97-100 \%$ before eradication [15].

Conclusively, SATs have several advantages in detection of $H$. pylori infection. We can rather easily get the stool samples non-invasively which makes it possible for mass screening in a community including detection in the children. Even the stool sample can be stored at freezing temperatures whereas using commercial detection kit9 it can be stored at ambient temperature for a long time, which makes it easy to transport. Since SATs do not require expensive chemical agents and special equipment, its price is lower than other 
non-invasive methods like urease breath test. Among the biochemical design of SATs, ICA-based tests are potential point-of-care detection kits since it is easy to perform and rapid for detection and hence it is a good alternative method for frontline medical staff in public health centers without laboratories [16].

Despite the advantages as mentioned above, SATs also have several disadvantages. Since the principle of SAT is an antigen-antibody reaction, differences in antigens used for SAT in different geographic regions may cause heterogeneity of results [17]. We should be conscious that the negative result of SAT may not indicate the absence of $H$. pylori infection because the low colonization of bacteria in stomach leads to low concentration of $H$. pylori antigen in the sample [18]. Regarding ICA-based methods, subjective interpretation of the results, especially for the tracing line, makes it difficult to diagnose accurately [13, 19].

We should also be cautious that in some special situations, the sensitivity of SAT may decrease, such as those for patients with gastrointestinal bleeding or for patients undergoing bismuth-based therapy [14].

\section{Polymerase chain reaction}

Polymerase chain reaction (PCR) is a reliable technology which is widely used in biology and medical research. Use of PCR for detection of $H$. pylori infection attracts many researchers' attention. Nowadays, there are several commercial detection kits available based on PCR. The common methods used for detection are real-time PCR, nested-PCR, and droplet digital PCR (ddPCR).

Some researchers have evaluated the diagnostic performance of commercial detection kits. Pichon et al. [20] assessed the performance of the Amplidiag H. pylori ClariR assay in detecting $H$. pylori infection and clarithromycin resistance in a large cohort study, and they demonstrated the good diagnostic performance of the assay in both of the aspects mentioned above. Redondo et al. [21] reported the diagnostic performance of commercial kits named LightMix® RT-PCR assay. This assay analyzed the melting curve to achieve simultaneous detection of $H$. pylori infection and clarithromycin resistance.

One of the important areas where PCR-based assay can be applied is the detection of antibiotic resistance and virulence factor, since antibiotic therapy is the foundation of the triple therapy for $H$. pylori eradication and the virulence factors are important for our clinicians to evaluate the infection. Rolon et al. [22] reported that apart from the high sensitivity and specificity of PCR-based assay, it may also be able to predict the prognosis of eradication treatment. The clarithromycin triple therapy was more likely successful when there is no prediction of resistance. Sun et al. [23] established a testing based on ddPCR to simultaneously detect $H$. pylori clarithromycin-resistant (mutant) and clarithromycin -susceptible (wild-type) 23S rRNA gene alleles in stool sample. Beckman et al. [24] also demonstrated that PCR-based assay can detect the presence of $H$. pylori DNA and mutations associated with resistance against clarithromycin at the same time. They also proposed two approaches to determine the existence of clarithromycin resistance. Talarico et al. [25] applied ddPCR-based $H$. pylori detection to disclose the relationship between significant variation in bacterial load among individuals and presence of the cagA virulence gene.

Another important application for PCR-based methods is to determine the prevalence of $H$. pylori infection and antimicrobial resistance in children. Beer-Davidson et al. [26] enrolled 188 samples from schoolchildren aged 6-9 years and 272 samples from healthy infants to develop and validate a multiplex real-time polymerase chain reaction (q-PCR) assay. They also evaluated the prevalence of clarithromycin resistance and cagA gene in $H$. pylori-positive samples and confirmed them with gene sequencing. Sicinschi et al. [27] used PCR-based methods to genotype alleles associated with virulence factors from stool sample of healthy Colombian children living in an area with high prevalence of gastric cancer. They revealed the high prevalence of disease-associated genotypes, such as cagA, hopQ, and vacA, and their results may prove that PCR-based methods can be used to screen for relevant genotypes in stool samples from a population. Scaletsky et al. [28] validate a novel bi-probe real-time assay in stool specimens from 217 dyspeptic children for $H$. pylori clarithromycin susceptibility testing, and Mishra et al. [29] also used nested-PCR to determine the prevalence of $H$. pylori in asymptomatic children.

Technology improvement is always the target for us in order to get more accurate diagnostic performance. Leonardi et al. [30] wondered whether the bead-beating step prior to DNA extraction can enhance the amount of DNA extracted, yet the results did not seem to support their hypothesis.

PCR-based $H$. pylori detections have several advantages. They can detect $H$. pylori infection and antimicrobial resistance simultaneously in short time. However, they have not been accepted for the routine testing like UBT because they have several disadvantages. First of all, PCR-based methods require specialized equipment and trained personnel which may not be easy for lower-income countries. Secondly, the concerns about the false-negative results and false-positive results still exist, since the PCR targets the DNA of active bacteria but DNA from dead bacteria may cause a falsepositive result, especially after the eradication treatment. As we know, $H$. pylori can transfer to coccoid form when it is difficult for them to survive in the environment [31] and this characteristic may obstruct the accurate detection of PCR-based methods [32]. The increasing presence of coccoid form and existence of mutation may lead to the 
false-negative result. The last but not the least is that some substances in the stool sample such as hemoglobin and its degradation products, polysaccharide complexes, heavy metals, and proteins, may inhibit the PCR-based testing. A research reported that the THD Fecal Test can eliminate PCR inhibiting substances such as polysaccharide complexes [33].

\section{Novel methods for detection from stool sample}

Apart from stool antigen test and PCR, there are some novel techniques developed recently. Ali et al. [34] reported a colorimetric paper device which can detect $H$. pylori sensitively and specifically. Their device was designed on the basis that the DNAzymes can specifically cleave RNA and can be activated by the crude extracellular mixture of $H$. pylori. What makes this device more meaningful is that it can be stored at ambient temperature for at least 130 days and still remain fully functional. Chen et al. [35] provided a new non-invasive detection method based on the combination of immunomagnetic beads and antigen-antibody reaction. The immunomagnetic beads conjugated with monoclonal antibodies sensitively recognized and captured the $H$. pylori, and the complex can be coupled with a polyclonal antibody-conjugating quantum dot probe. After that, fluorescence spectrometer was used to achieve ultrasensitive detection. Jain et al. [36] utilized a clustered metallic nanoparticle along with carbon nanomaterial and conducted polymer-based ultrasensitive immunosensor for H. pylori detection. Their device provided high loading of CagA antibody and resulted into a great diagnostic performance. All these explorations broaden our horizons and provide more possibility for accurate diagnosis of $H$. pylori infection.

\section{Discussion}

$H$. pylori infection is the cause of many gastroduodenal diseases and over half of the population worldwide are infected with it. Ding et al. [37] conducted a prospective, cross-sectional, population-based study involving 3491 children (0-18 years) in total. They found that the overall infection rate was $6.8 \%$ with no significant differences between genders. Infection rates between regions were significantly different $(P<0.05)$ and increased with age. Because of the great prevalence of $H$. pylori infection, increasing infection rate with age, and the potential pathogenicity, it is important to detect $H$. pylori and antibiotic resistance accurately both in adult and children whether they are symptomatic or not.

There are several methods for detection of $H$. pylori infection and nowadays we usually utilize UBT as the first choice of detection. However, it has several disadvantages, such as the need for expensive equipment and reagents and well-trained experts to interpret the results, which limits its application. Also, UBT does not perform well in children because it may be difficult for young children and infants to cooperate. Therefore, detection based on stool sample would be a potential and promising alternative for detection of $H$. pylori infection and the mass screening.

Detections for $H$. pylori from stool sample have several points worthy of our attention. For SAT, firstly, we should be cautious about the shape of stool and the interval between sample collection and detection. Watery feces may provide false-negative results because of antigen dilution. Assessments using excreted feces become impossible $24-48 \mathrm{~h}$ after collection, but this may be solved by using a robust sampling kit. Secondly, we should better conduct local validation of antigen used in SAT if conditions permit [15]. Thirdly, we should be careful about patients with severe atrophic gastritis and intestinal metaplasia. Because of the decreased colonization of $H$. pylori, it may lead to a false-negative result [38]. Although most studies have shown that the effect of PPI on SAT is less effective on UBT [39, 40], we still recommend that clinicians carefully evaluate the impact of ongoing treatments that include PPI, antibiotics, and bismuth. In addition, the interval between drug withdrawal and testing should also attract our attention.

Regarding of PCR-based methods, we should be worried about the quality and amount of DNA extracted, the design of target sequence, and the selection of amplification protocol. A progress which can stabilize the $H$. pylori DNA and enhance the amount of the extract may help a lot. It is suggested that nested-PCR is more sensitive than the regular PCR because it involves two rounds of amplification, which makes it able to amplify the target sequence in a lower concentration [41]. What's more, combination of several target genes for detection, such as ureA, glmM, and vacA, may help to improve the diagnostic performance by reducing the possibility of missed detection [42].

For all the testing used stool specimens, we should be aware of external contamination because it can interfere with the normal results. Another point worthy of our attention is that gastrointestinal tracts in children and those of adults are different, such as composition of gut flora and passage time of stool [43].

\section{Conclusion}

Detection of $H$. pylori infection and antibiotic resistance is an important issue for prevention of several gastroduodenal diseases like gastric cancer. Detections from stool sample have several advantages such as simplicity of sample collection yet they also have many limitations. In this review, 
we summarized what the researchers have reported, the new progress in methodology, and some aspects we should pay attention to when we utilize these methods. We hope this review can help clinicians choose the suitable technique for detection in their clinical practice.

Author contribution Enming Qiu brought up the idea and drafted the manuscript. Shuai Han performed the literature search and data analysis. Zhou Li critically revised the manuscript. All authors read and approved the final manuscript.

Availability of data and material Not applicable.

Code availability Not applicable.

\section{Declarations}

Conflict of interest The authors declare no competing interests.

Ethics approval and consent to participate Not applicable.

Consent for publication All the authors agreed to publish the manuscript.

Open Access This article is licensed under a Creative Commons Attribution 4.0 International License, which permits use, sharing, adaptation, distribution and reproduction in any medium or format, as long as you give appropriate credit to the original author(s) and the source, provide a link to the Creative Commons licence, and indicate if changes were made. The images or other third party material in this article are included in the article's Creative Commons licence, unless indicated otherwise in a credit line to the material. If material is not included in the article's Creative Commons licence and your intended use is not permitted by statutory regulation or exceeds the permitted use, you will need to obtain permission directly from the copyright holder. To view a copy of this licence, visit http://creativecommons.org/licenses/by/4.0/.

\section{References}

1. Marshall BJ, Warren JR (1984) Unidentified curved bacilli in the stomach of patients with gastritis and peptic ulceration. Lancet (London, England) 1(8390):1311-1315. https://doi.org/10.1016/ s0140-6736(84)91816-6

2. Wroblewski LE, Peek RM Jr, Wilson KT (2010) Helicobacter pylori and gastric cancer: factors that modulate disease risk. Clin Microbiol Rev 23(4):713-739. https://doi.org/10.1128/cmr. 00011-10

3. Camilo V, Sugiyama T, Touati E (2017) Pathogenesis of Helicobacter pylori infection. Helicobacter 22(Suppl):1. https://doi.org/ 10.1111/hel.12405

4. Mitchell H, Katelaris P (2016) Epidemiology, clinical impacts and current clinical management of Helicobacter pylori infection. Med J Aust 204(10):376-380. https://doi.org/10.5694/mja16.00104

5. Ke H, Li J, Lu B, Yang C, Wang J, Wang Z, Liu L, Chen Y (2021) The appropriate cutoff gastric $\mathrm{pH}$ value for Helicobacter pylori eradication with bismuth-based quadruple therapy. Helicobacter 26(1):e12768. https://doi.org/10.1111/hel.12768
6. Khalilpour A, Kazemzadeh-Narbat M, Tamayol A, Oklu R, Khademhosseini A (2016) Biomarkers and diagnostic tools for detection of Helicobacter pylori. Appl Microbiol Biotechnol 100(11):4723-4734. https://doi.org/10.1007/s00253-016-7495-7

7. Halland M, Haque R, Langhorst J, Boone JH, Petri WA (2021) Clinical performance of the H. PYLORI QUIK CHEK ${ }^{\mathrm{TM}}$ and $\mathrm{H}$. PYLORI CHEK ${ }^{\mathrm{TM}}$ assays, novel stool antigen tests for diagnosis of Helicobacter pylori. European journal of clinical microbiology \& infectious diseases : official publication of the European Society of Clinical Microbiology 40(5):1023-1028. https://doi. org/10.1007/s10096-020-04137-7

8. Fang YJ, Chen MJ, Chen CC, Lee JY, Yang TH, Yu CC, Chiu MC, Kuo CC, Weng YJ, Bair MJ, Wu MS, Luo JC, Liou JM (2020) Accuracy of rapid Helicobacter pylori antigen tests for the surveillance of the updated prevalence of H. pylori in Taiwan. $\mathrm{J}$ Formosan Med Assoc Taiwan yi zhi 119(11):1626-1633. https:// doi.org/10.1016/j.jfma.2019.12.003

9. Opekun AR, Zierold C, Rode A, Blocki FA, Fiorini G, Saracino IM, Vaira D, Sutton FM (2020) Clinical performance of the automated LIAISON® Meridian H. pylori SA Stool Antigen Test. BioMed research international 2020:7189519. https://doi.org/10. 1155/2020/7189519

10. Kakiuchi T, Okuda M, Hashiguchi K, Imamura I, Nakayama A, Matsuo M (2019) Evaluation of a novel stool antigen rapid test kit for detection of Helicobacter pylori infection. Journal of clinical microbiology 57(3). https://doi.org/10.1128/jcm.01825-18

11. Moon HW, Lee SY, Hur M, Yun YM (2018) Characteristics of Helicobacter pylori-seropositive subjects according to the stool antigen test findings: a prospective study. Korean J Intern Med 33(5):893-901. https://doi.org/10.3904/kjim.2016.353

12. Yan J, Yamaguchi T, Odaka T, Suzuki T, Ohyama N, Hara T, Sudo K, Nakamura K, Denda T, Takiguchi N, Yokosuka O, Nomura F (2010) Stool antigen test is a reliable method to detect Helicobacter pylori in the gastric remnant after distal gastrectomy for gastric cancer. J Clin Gastroenterol 44(1):73-74. https://doi.org/10.1097/ MCG.0b013e3181aae65e

13. Zhou X, Su J, Xu G, Zhang G (2014) Accuracy of stool antigen test for the diagnosis of Helicobacter pylori infection in children: a meta-analysis. Clin Res Hepatol Gastroenterol 38(5):629-638. https://doi.org/10.1016/j.clinre.2014.02.001

14. Korkmaz H, Kesli R, Karabagli P, Terzi Y (2013) Comparison of the diagnostic accuracy of five different stool antigen tests for the diagnosis of Helicobacter pylori infection. Helicobacter 18(5):384-391. https://doi.org/10.1111/hel.12053

15. Kato M, Ota H, Okuda M, Kikuchi S, Satoh K, Shimoyama T, Suzuki H, Handa O, Furuta T, Mabe K, Murakami K, Sugiyama T, Uemura N, Takahashi S (2019) Guidelines for the management of Helicobacter pylori infection in Japan: 2016 Revised Edition. Helicobacter 24 (4):e12597. https://doi.org/10.1111/hel.12597

16. Lee YC, Tseng PH, Liou JM, Chen MJ, Chen CC, Tu CH, Chiang TH, Chiu HM, Lai CF, Ho JC, Wu MS (2014) Performance of a one-step fecal sample-based test for diagnosis of Helicobacter pylori infection in primary care and mass screening settings. Journal of the Formosan Medical Association = Taiwan yi zhi 113 (12):899-907. https://doi.org/10.1016/j.jfma.2012.05.014

17. Lario S, Ramírez-Lázaro MJ, Montserrat A, Quílez ME, Junquera F, Martínez-Bauer E, Sanfeliu I, Brullet E, Campo R, Segura F, Calvet X (2016) Diagnostic accuracy of three monoclonal stool tests in a large series of untreated Helicobacter pylori infected patients. Clin Biochem 49(9):682-687. https://doi.org/10.1016/j. clinbiochem.2016.01.015

18. El-Shabrawi M, El-Aziz NA, El-Adly TZ, Hassanin F, Eskander A, Abou-Zekri M, Mansour H, Meshaal S (2018) Stool antigen detection versus (13)C-urea breath test for non-invasive diagnosis of pediatric Helicobacter pylori infection in a limited resource 
setting. Arch Med Sci: AMS 14(1):69-73. https://doi.org/10.5114/ aoms.2016.61031

19. Calvet X, Lario S, Ramírez-Lázaro MJ, Montserrat A, Quesada M, Reeves L, Masters H, Suárez-Lamas D, Gallach M, Miquel M, Martínez-Bauer E, Sanfeliu I, Segura F (2010) Accuracy of monoclonal stool tests for determining cure of Helicobacter pylori infection after treatment. Helicobacter 15(3):201-205. https://doi.org/10.1111/j. 1523-5378.2010.00757.x

20. Pichon M, Pichard B, Barrioz T, Plouzeau C, Croquet V, Fotsing G, Chéron A, Vuillemin É, Wangermez M, Haineaux PA, Vasseur P, Thiebault Q, Lefèvre C, de Singly A, Cremniter J, Broutin L, Michaud A, Silvain C, Burucoa C (2020) Diagnostic accuracy of a noninvasive test for detection of Helicobacter pylori and resistance to clarithromycin in stool by the Amplidiag H. pylori+ClariR Real-Time PCR Assay. Journal of clinical microbiology 58 (4). https://doi.org/10.1128/jcm. 01787-19

21. Redondo JJ, Keller PM, Zbinden R, Wagner K (2018) A novel RTPCR for the detection of Helicobacter pylori and identification of clarithromycin resistance mediated by mutations in the 23S rRNA gene. Diagn Microbiol Infect Dis 90(1):1-6. https://doi.org/10.1016/j. diagmicrobio.2017.09.014

22. Marrero Rolon R, Cunningham SA, Mandrekar JN, Polo ET, Patel R (2021) Clinical evaluation of a real-time PCR assay for simultaneous detection of Helicobacter pylori and genotypic markers of clarithromycin resistance directly from stool. Journal of clinical microbiology 59 (5). https://doi.org/10.1128/jcm.03040-20

23. Sun L, Talarico S, Yao L, He L, Self S, You Y, Zhang H, Zhang Y, Guo Y, Liu G, Salama NR, Zhang J (2018) Droplet digital PCR-based detection of clarithromycin resistance in Helicobacter pylori isolates reveals frequent heteroresistance. Journal of clinical microbiology 56 (9). https://doi.org/10.1128/jcm.00019-18

24. Beckman E, Saracino I, Fiorini G, Clark C, Slepnev V, Patel D, Gomez C, Ponaka R, Elagin V, Vaira D (2017) A novel stool PCR test for Helicobacter pylori may predict clarithromycin resistance and eradication of infection at a high rate. J Clin Microbiol 55(8):2400-2405. https://doi.org/10.1128/jcm.00506-17

25. Talarico S, Safaeian M, Gonzalez P, Hildesheim A, Herrero R, Porras C, Cortes B, Larson A, Fang FC, Salama NR (2016) Quantitative detection and genotyping of Helicobacter pylori from stool using droplet digital PCR reveals variation in bacterial loads that correlates with cagA virulence gene carriage. Helicobacter 21(4):325-333. https:// doi.org/10.1111/hel.12289

26. Beer-Davidson G, Hindiyeh M, Muhsen K (2018) Detection of Helicobacter pylori in stool samples of young children using real-time polymerase chain reaction. Helicobacter 23 (1). https://doi.org/10. 1111/hel.12450

27. Sicinschi LA, Correa P, Bravo LE, Peek RM Jr, Wilson KT, Loh JT, Yepez MC, Gold BD, Thompson DT, Cover TL, Schneider BG (2012) Non-invasive genotyping of Helicobacter pylori cagA, vacA, and hopQ from asymptomatic children. Helicobacter 17(2):96-106. https://doi.org/10.1111/j.1523-5378.2011.00919.x

28. Scaletsky IC, Aranda KR, Garcia GT, Gonçalves ME, Cardoso SR, Iriya K, Silva NP (2011) Application of real-time PCR stool assay for Helicobacter pylori detection and clarithromycin susceptibility testing in Brazilian children. Helicobacter 16(4):311-315. https://doi.org/10. 1111/j.1523-5378.2011.00845.x

29. Mishra S, Singh V, Rao GR, Dixit VK, Gulati AK, Nath G (2008) Prevalence of Helicobacter pylori in asymptomatic subjects--a nested PCR based study. Infection, genetics and evolution : journal of molecular epidemiology and evolutionary genetics in infectious diseases 8 (6):815-819. https://doi.org/10.1016/j.meegid.2008.08.001

30. Leonardi M, La Marca G, Pajola B, Perandin F, Ligozzi M, Pomari E (2020) Assessment of real-time PCR for Helicobacter pylori DNA detection in stool with co-infection of intestinal parasites: a comparative study of DNA extraction methods. BMC Microbiol 20(1):131. https://doi.org/10.1186/s12866-020-01824-5

31. Kadkhodaei S, Siavoshi F, Akbari Noghabi K (2020) Mucoid and coccoid Helicobacter pylori with fast growth and antibiotic resistance. Helicobacter 25(2):e12678. https://doi.org/10.1111/hel.12678

32. Leal YA, Cedillo-Rivera R, Simón JA, Velázquez JR, Flores LL, Torres J (2011) Utility of stool sample-based tests for the diagnosis of Helicobacter pylori infection in children. J Pediatr Gastroenterol Nutr 52(6):718-728. https://doi.org/10.1097/MPG.0b013e3182077d33

33. Giorgio F, Ierardi E, Sorrentino C, Principi M, Barone M, Losurdo G, Iannone A, Giangaspero A, Monno R, Di Leo A (2016) Helicobacter pylori DNA isolation in the stool: an essential pre-requisite for bacterial noninvasive molecular analysis. Scand J Gastroenterol 51(12):1429-1432. https://doi.org/10.1080/00365521.2016.1216592

34. Ali MM, Wolfe M, Tram K, Gu J, Filipe CDM, Li Y, Brennan JD (2019) A DNAzyme-Based Colorimetric Paper Sensor for Helicobacter pylori. Angew Chem Int Ed Engl 58(29):9907-9911. https:// doi.org/10.1002/anie.201901873

35. Chen L, Li X, Zou T, Wang T, Cui X, Chen Y, Zhang C, Zhao S (2019) Ultrasensitive detection of H. pylori in human feces based on immunomagnetic bead capture and fluorescent quantum dots. The Analyst 144(13):4086-4092. https://doi.org/10.1039/c9an00193j

36. Jain U, Gupta S, Soni S, Khurana MP, Chauhan N (2020) Triplenanostructuring-based noninvasive electro-immune sensing of CagA toxin for Helicobacter pylori detection. Helicobacter 25(4):e12706. https://doi.org/10.1111/hel.12706

37. Ding Z, Zhao S, Gong S, Li Z, Mao M, Xu X, Zhou L (2015) Prevalence and risk factors of Helicobacter pylori infection in asymptomatic Chinese children: a prospective, cross-sectional, population-based study. Aliment Pharmacol Ther 42(8):1019-1026. https://doi.org/10. 1111/apt.13364

38. Shimoyama T, Oyama T, Matsuzaka M, Danjo K, Nakaji S, Fukuda S (2009) Comparison of a stool antigen test and serology for the diagnosis of Helicobacter pylori infection in mass survey. Helicobacter 14(2):87-90. https://doi.org/10.1111/j.1523-5378.2009.00672.x

39. Shimoyama $\mathrm{T}$ (2013) Stool antigen tests for the management of Helicobacter pylori infection. World J Gastroenterol 19(45):8188-8191. https://doi.org/10.3748/wjg.v19.i45.8188

40. Kodama M, Murakami K, Okimoto T, Fukuda Y, Shimoyama T, Okuda M, Kato C, Kobayashi I, Fujioka T (2012) Influence of proton pump inhibitor treatment on Helicobacter pylori stool antigen test. World J Gastroenterol 18(1):44-48. https://doi.org/10.3748/wjg.v18. i1. 44

41. Šeligová B, Lukáč L, Bábelová M, Vávrová S, Sulo P (2020) Diagnostic reliability of nested PCR depends on the primer design and threshold abundance of Helicobacter pylori in biopsy, stool, and saliva samples. Helicobacter 25(2):e12680. https://doi.org/10.1111/ hel.12680

42. Wongphutorn P, Chomvarin C, Sripa B, Namwat W, Faksri K (2018) Detection and genotyping of Helicobacter pylori in saliva versus stool samples from asymptomatic individuals in Northeastern Thailand reveals intra-host tissue-specific $\mathrm{H}$. pylori subtypes. BMC Microbiology 18(1):10. https://doi.org/10.1186/s12866-018-1150-7

43. Lottspeich C, Schwarzer A, Panthel K, Koletzko S, Rüssmann H (2007) Evaluation of the novel Helicobacter pylori ClariRes real-time PCR assay for detection and clarithromycin susceptibility testing of $\mathrm{H}$. pylori in stool specimens from symptomatic children. J Clin Microbiol 45 (6):1718-1722. https://doi.org/10.1128/jcm.00103-07

Publisher's note Springer Nature remains neutral with regard to jurisdictional claims in published maps and institutional affiliations. 